\title{
La función reguladora del Estado y el Derecho
}

Alberto Giraldo Saavedra ${ }^{1}$

\begin{abstract}
Resumen
A pesar de las dificultades de carácter teórico y conceptual, la regulación se ha convertido en un tema relevante para el análisis de las transformaciones del Estado y el Derecho que requiere ser estudiado para alcanzar una mejor comprensión de tales transformaciones.
\end{abstract}

Con el presente artículo se pretende hacer una aproximación conceptual e histórica del fenómeno de la regulación, del diseño institucional que se viene adoptando por parte del Estado para su ejercicio y de la necesidad de adoptar algún tipo de metodología que permita determinar la capacidad institucional para el cumplimiento de dicha función.

Palabras clave: Regulación, Estado intervencionista, derecho regulativo, Agencias Reguladoras Independientes, Autoridades Administrativas Independientes

\section{The regulatory role of the State and Law}

\begin{abstract}
Despite the difficulties of theoretical and conceptual, regulation has become an important issue for the analysis of changes in the state and the law that needs to be studied to achieve a better understanding of such transformations.

In this article we try to do a conceptual and historical phenomenon of regulation, institutional design is being adopted by the State for the exercise
\end{abstract}


and the need for some type of methodology to determine the institutional capacity for fulfilling this function

Key words: Regulation, interventionist state, regulatory law, Independent Regulatory Agencies, Independent Administrative Authorities

Recibido: 02 de marzo 2012

Aceptado: 06 de junio 2012

\section{Aproximación conceptual al fenómeno de la regulación}

A pesar de ser un tema de atención de vieja data, por parte del derecho, la regulación adquiere una gran relevancia a partir de la década de los setenta, como consecuencia de los grandes cambios de carácter económico, político y social que enfrentan la mayoría de los países, con ocasión de las alteraciones dadas en el modelo de desarrollo y su impacto en el Estado, el derecho y la administración pública, particularmente en sus relaciones con la sociedad y el mercado.

A su vez, la regulación, entendida en una primera aproximación conceptual, como una forma de intervención del Estado en la economía y la sociedad, es un fenómeno que pone de presente las grandes transformaciones a las que han sido sometidas las instituciones, desde que la ideología liberal relegara el rol del Estado a garantizar las reglas del juego que se generan como resultado de las relaciones entre los agentes económicos, llamadas leyes de racionalidad económica, pasando por un período de fuerte intervención del Estado en la esfera económica y social, hasta llegar al momento actual en el que, desde distintos frentes se plantea la necesidad de avanzar en procesos de desregulación, como respuesta y posible solución a los problemas surgidos en el llamado Estado de bienestar, y de manera muy puntual, a la crisis fiscal del Estado.

Al término regulación se le han dado múltiples acepciones, dependiendo de las perspectivas teóricas, ideológicas y disciplinares desde las cuales se pretende abordar su estudio. Pero adicionalmente, son diversas las aproximaciones conceptuales que se hacen al fenómeno de la regulación desde el derecho, la economía, la sociología, la ciencia política y la administración, sea ésta, pública o privada. Por tal razón y con el único propósito de destacar la complejidad a la cual se debe enfrentar todo el que quiera abordar su estudio, se presentan algunos de los acercamientos que intentan definirla o conceptualizarla.

En ocasiones, el vocablo «regulación» es utilizado como sinónimo de reglamentación, dentro de un sentido amplio de existencia o de formulación de 
reglas en cualquiera de los ámbitos de la vida económica y social, siendo frecuente su utilización como una manera de designar tanto las presencia de reglas de derecho sobre una cuestión determinada, como la actividad y el proceso de producción de las mismas (Oramas, 2003). En este sentido, la regulación estaría llamada a introducir reglas en un objeto social para asegurar su estabilidad y permanencia en el tiempo, reconociendo los cambios que se puedan suscitar. Pero a la vez, la regulación en sentido amplio, como veremos más adelante, amplía su radio de acción a una gran cantidad de actividades de carácter técnico especializado como resultado de la división social y técnica del trabajo.

Para la sociología, la relación social se manifiesta por una regulación, por la producción y el permanente ajuste de reglas dentro de la interacción social que, obviamente están en estrecha relación de interdependencia con el conjunto creencias y valores construido por el grupo social objeto de la regulación. De otra parte, para la teoría económica, bajo el término de regulación se comprende, «no solamente el conjunto de mecanismos que concurren a la producción de un sistema económico, caracterizado por una cierta articulación de relaciones sociales fundamentales o formas institucionales (la forma del Estado, la moneda, las relaciones sociales), sino la obra misma de estos dispositivos»» (Oramas, 2003:461).

Para la ciencia política y la ciencia administrativa, la acción pública constituye una de las formas de intervención del Estado en la economía con el propósito de corregir las deficiencias del mercado, que garanticen la operación del mismo, para lo cual, el Estado debe acudir al derecho con el fin de regular las relaciones entre los diferentes agentes económicos. Sin olvidar que la intervención y su correspondiente regulación no presentan las mismas características a lo largo del tiempo, como podría llegar a pensarse. Muy por el contrario, ha variado sustancialmente, dependiendo, el país que se pretenda estudiar, del momento histórico que se quiera analizar y de las concepciones teóricas ${ }^{2}$ sobre las que se fundamente dicha intervención.

La utilización del término regulación, por parte de la ciencia política ha adquirido tanta importancia que, como veremos más adelante, es desde la perspectiva económica y política, en un mundo globalizado, que se propone el concepto de Estado regulador como sustituto del Estado intervencionista, especialmente en los países avanzados, o complementario en los países en vía de desarrollo.

La regulación económica se origina, fundamentalmente, como consecuencia de las llamadas fallas del mercado ${ }^{3}$ y con el propósito de subsanarlas, las

2 Un ejercicio de síntesis muy bien logrado que sirve de guía para conocer con mayor profundidad el debate teórico acerca de la regulación desde una perspectiva económica y política aparece Rivera Urrutia, 2004.

3 La teoría de las fallas del mercado plantea que la economía, regida por las leyes del mercado, no es necesariamente eficiente. Desde esta perspectiva teórica se afirma que los mercados no producen resultados eficientes cuando se presenta algún aspecto que contraríe alguno de sus supuestos: racionalidad, competencia perfecta, mercados completos, información completa e inexistencia de costos sociales y de transacción. 
cuales, se pueden presentar por diversas razones, entre las que se desatacan: en primer lugar, la existencia de estructuras de mercado poco competitivas o el surgimiento de economías de escala y rendimientos decrecientes, asociados a la incorporación de progreso técnico. En segundo lugar, la presencia de mercados segmentados e incompletos, en los que no se produce determinado tipo de bienes a los precios vigentes o simplemente, la producción de bienes es insuficiente frente a la demanda de la economía. En tercer lugar, la información con la que deben tomar decisiones racionales los agentes económicos no está disponible y en ocasiones es incompleta y asimétrica, surgiendo problemas de incentivos, relacionados con la conducta maximizadora de los individuos. ${ }^{4}$ En cuarto lugar, los derechos de propiedad no aparecen claramente definidos, dando lugar a que a los agentes económicos se les dificulte acordar la distribución de los costos y beneficios sociales de las actividades productivas en las que participan. ${ }^{5}$

Por supuesto que existen muchas más razones que permitirían tener una compresión más amplia de las fallas del mercado, que no van a ser tratadas en este escrito por no ser el propósito del mismo, pero que vistas en conjunto constituyen uno de los argumentos fundamentalmente destacados para justificar la presencia del Estado en la economía, bien sea como un agente económico más, como director general de la economía o como garante del crecimiento y desarrollo con el propósito de corregir las ineficiencias que el funcionamiento del mercado genera.

De otra parte, desde la administración, una de las muchas acepciones que se le asigna al término regulación, consiste en designar una práctica administrativa muy común dentro los especialistas de las finanzas públicas y de los expertos en derecho financiero, la expresión «regulación presupuestal», pero a la vez, es utilizado ampliamente con el fin de referirse a la estandarización de procesos y procedimientos que se requieren en las organizaciones para la producción de un bien o la prestación de un servicio, o para la reglamentación de los aspectos técnicos de las diferentes actividades que deben desarrollar con el propósito de alcanzar los objetivos y el cumplimiento de las funciones para las que fueron creadas.

\section{Aproximación histórica al fenómeno de la regulación}

La gran depresión económica o crisis mundial del capitalismo de fines los años veinte, extendida durante la década de los treinta, constituye el fin de una era ampliamente conocida como laissez-faire en la que la ideología liberal

\footnotetext{
4 La conducta maximizadora hace referencia al daño moral y a la selección adversa. El daño moral tiene que ver con el aprovechamiento de la información asimétrica que hace un individuo en el intercambio, al realizar acciones que afectan a la otra parte sin que ésta pueda hacer nada por falta de información. En tanto que la selección adversa, se refiere a que, en el intercambio, un solo individuo tiene información sobre la calidad de un bien o servicio que es importante, pero desconocida para el otro individuo que participa en el intercambio
} 
le había planteado al Estado una intervención mínima en la economía y en la organización de la vida social, limitándolo a definir las reglas del juego que, de alguna manera, surgían de las leyes propias de la racionalidad económica, y por lo tanto, su función se reducía a la de simple espectador, o en el mejor de los casos, a la de árbitro del juego económico y social.

Durante dicho período el Estado no tenía iniciativa económica y social, simplemente, debía garantizar los ideales del individualismo. Para ello, el Estado acudía al derecho como un instrumento dotado de racionalidad formal, ${ }^{6}$ para regular las relaciones entre los individuos sin ninguna pretensión, distinta de la de promover relaciones armoniosas entre los asociados, es decir, que el Estado se limitaba a utilizar el derecho para establecer unas reglas generales de actuación para la sociedad, de carácter puramente formal. En palabras de Calvo García «El Estado debía limitarse a garantizar un entramado mínimo de expectativas para que la acción responsable de los individuos pudiera desenvolverse con libertad y seguridad. Las funciones que se asignan al derecho y al Estado en la ideología jurídica liberal tendrían como único fin la consolidación y el aseguramiento de un marco racional-formal de autonomía protegida» (Calvo García, 2005: 22).

Esta actitud, un tanto pasiva del Estado, si así puede llamarse, comienza a variar en la medida en que se plantea como una de las soluciones para salir de la crisis o depresión económica, la intervención directa del Estado en los asuntos económicos, mediante incrementos importantes de la inversión pública, dada la incapacidad del laissez-faire para realizar una eficiente asignación de recursos que promoviera el equilibrio y crecimiento económico.

El pensamiento económico que acude a salvar al capitalismo de la situación de crisis por la que atraviesa, consiste en proponer el incremento del gasto público en períodos de recesión con el fin de estimular la inversión, el empleo y el consumo. En tal sentido y como respuesta a dicho planteamiento, se inicia un período en el que se le asignan, paulatinamente, nuevas funciones y responsabilidades al Estado, viéndose en la obligación de tener que abandonar el papel de árbitro que le asignó la ideología liberal, para iniciar el tránsito hacia el llamado Estado keynesiano o interventor, en el que tendrá que asumir un rol mucho más activo y determinante para la vida económica y social.

Por tal razón no es nada extraño que, en adelante, veamos un Estado que interviene directamente en los procesos económicos, no solo como un agente económico más, sino como el gran orientador y director general de la economía, promotor del crecimiento económico y responsable directo de la justicia y la equidad social, motivo por la cual, muy seguramente, una de las primeras 
incursiones, absolutamente definitiva, para superar la crisis, fue la reconstrucción del escenario de operaciones de la guerra, mediante el plan Marshall.

En la mayoría de los países del mundo el Estado va a ser el responsable del diseño, construcción y puesta en operación de las grandes obras que marcarán el rumbo del crecimiento económico durante el período que va desde los inicios de la segunda posguerra, hasta finales de los sesenta, en algunos Estados, y setenta y ochenta en otros. No hay que olvidar que en muchos países, fue el Estado, directamente o a través de terceros el que construyó y adecuó gran parte de la infraestructura física y social, tales como carreteras, puertos, aeropuertos, hidroeléctricas, termoeléctricas, escuelas, colegios, universidades, hospitales, puestos y centros de salud, así como la creación de todo tipo de empresas industriales, comerciales, de servicios públicos domiciliarios o de carácter social.

Pero adicionalmente, en el plano económico, se le atribuyó al Estado el papel fundamental en la promoción del desarrollo. Ello significaba que el Estado debía dirigir el proceso económico, canalizar recursos subsidiados hacia la producción y el empleo, y crear protecciones especiales para actividades productivas en las que existía un interés especial.

Se dice que con Keynes, el discurso social del Estado de bienestar se articuló con el económico. El gasto social hacía parte del activismo fiscal (Para una mayor comprensión del tema, ver Giraldo, 2002), y la tributación directa se justificaba porque la propensión a ahorrar era mayor en las rentas más altas, con las que substraían una mayor parte del ingreso de la demanda efectiva. Para reactivar la demanda era necesario gravar las rentas altas para que tales recursos pudieran ser gastados vía sector público (Giraldo, 2002: 45).

Pero además del activismo fiscal, el intervencionismo también hace referencia a la distribución secundaria del ingreso. Mientras el mercado hace una asignación primaria del ingreso, de acuerdo con la remuneración de los factores de producción, el Estado, a través de las finanzas públicas, altera esa distribución en aras de una mayor igualdad, porque redistribuye las rentas a través impuestos progresivos que gravan el capital y de transferencias directas (pensiones) o indirectas (subsidios a los productos de la canasta familiar) y prestación de servicios como salud y educación (Giraldo, 2002: 46).

Los logros innegables, alcanzado por el Estado se ven empañados ante la falta de efectividad de la expansión del gasto público para reducir el desempleo, el crecimiento desmesurado de su aparato administrativo, los altos niveles de ineficiencia y corrupción, lo cual empezó a significar una pesada carga que la sociedad debía soportar y financiar con sus impuestos.

Esta situación condujo a que se señalara que en muchos casos los beneficios que se otorgaban por parte del Estado se habían convertido en privilegios 
y monopolios al servicio de los grupos dominantes. El aparato estatal se transformó en un espacio cerrado y controlado por burócratas en el cual los más corruptos utilizaban las regulaciones como un instrumento para extraer rentas que se derivaban de su capacidad para entorpecer el proceso de desarrollo.

Poco a poco los Estados se burocratizaron, perdiendo cada vez más los vínculos con la sociedad civil que decían representar. En mayor o menor grado, dependiendo de cada caso, estaban al servicio de las burocracias y/o de los sectores económicos privilegiados. Esto creó una crisis de legitimidad en Europa y Estados Unidos a comienzos de los años 70, lo que llevó a la necesidad de introducir reformas significativas a los aparatos estatales, y fue el momento en el que hizo su presencia el neoliberalismo.

Las reformas se dirigieron a redefinir el papel del Estado, concentrándolo en las áreas en las cuales se decía que era más necesario y retirándolo de aquellas en que el sector privado podía cumplir un mejor papel, desregulando los controles $\mathrm{y}$ fortaleciendo la descentralización política y administrativa.

La intervención estatal fue considerada la responsable directa y principal del descalabro, lo cual condujo a que se hiciera una especie de redescubrimiento de las ventajas del mercado, en contraposición de las supuestas perversidades de la intervención del Estado, demostrado empíricamente por la gran crisis fiscal a la que han tenido que enfrentarse la gran mayoría de países en el mundo, que para el caso de los países de América Latina se agrava, aún más, por el crecimiento exagerado de la deuda pública.

Para resolver los problemas de la crisis del Estado, se formulan y en algunos casos se adoptan, una serie de recetas que recibieron el nombre de «Consenso de Washington», denominado así por la coincidencia de recomendaciones de política económica formuladas por los organismos promotores de las reformas, todos ellos domiciliados en la capital de Estados Unidos. En un resumen elaborado por quien más contribuyó a la difusión del denominado «Consenso», se afirma que éste consistía en recomendar diez ingredientes de política económica: 1) disciplina fiscal; 2) priorización del gasto público en áreas de alto retorno económico; 3) reforma tributaria; 4) tasas positivas de interés fijadas por el mercado; 5) tipos de cambio competitivos y liberalización financiera; 6) políticas comerciales liberales; 7) apertura a la inversión extranjera; 8) privatizaciones; 9) desregulación amplia; 10) protección a la propiedad privada (Vilas, 2000).

En América Latina, la adopción de estas políticas por gobiernos surgidos de elecciones contribuyó a modificar el significado asignado al «Consenso»: éste no se referiría únicamente a un acuerdo entre organizaciones burocráticas impersonales, sino a la decisión de la ciudadanía de votar por los candidatos dispuestos a llevar el programa a la práctica (Vilas, 2000:27). Varios de los 
ingredientes del paquete neoliberal habían sido parte integral de la política económica de regímenes autoritarios o francamente dictatoriales.

Hasta la década de 1980, esta circunstancia abonó la identificación entre políticas neoliberales y autoritarismo político difundida en amplios sectores de la opinión pública y en ámbitos académicos. En cambio, en los escenarios diseñados por la crisis y las «transiciones a la democracia», el programa neoliberal fue asumido por un buen número de los gobiernos surgidos de procesos electorales. La promoción de la economía de mercado y el levantamiento de los mecanismos de intervención estatal se convirtieron en el núcleo estratégico de las «nuevas democracias» latinoamericanas, que pasaron a recibir la denominación de democracias de mercado.

El papel del Estado debería reducirse a su nivel mínimo de provisión de bienes públicos, ${ }^{7}$ interpretados éstos en un sentido restrictivo. El desmantelamiento de los mecanismos de intervención requirió, sin embargo, una previa concentración de facultades decisorias en su aparato institucional, para impulsar la apertura y las desregulaciones, vencer las resistencias y modificar los equilibrios preexistentes.

El reconocimiento de la gestión pública por parte de la economía y de las relaciones sociales fue viabilizado por el fortalecimiento del Estado como expresión institucional del poder político. La manifestación más frecuente de esta ampliación de la soberanía estatal, es decir, de su capacidad para imponer decisiones con autoridad suprema respecto de la población de un territorio fue la concentración de facultades en el ámbito del gobierno central y, en particular, del poder ejecutivo: delegación de facultades de competencia parlamentaria, normas legales de excepción o de emergencia, y similares.

La reestructuración estuvo acompañada por un conjunto de manifestaciones de deterioro social que, contrariamente a las hipótesis o justificaciones de los diseñadores y ejecutores, fueron más allá del momento inicial del ajuste y subsisten hasta el presente: fragmentación de los mercados de trabajo con tasas altas de desempleo abierto, subempleo; deterioro de las remuneraciones reales; aumento de la población en condiciones de pobreza; retracción y pérdida de calidad de la cobertura en servicios básicos; degradación ambiental; incremento de la inseguridad; fuertes desigualdades sociales.

El balance del ajuste puso de relieve que no sólo en el terreno de los asuntos sociales y del bienestar los resultados distaban de ser satisfactorios. El traspaso al mercado de activos y de decisiones, y la desregulación amplia del comercio y las finanzas, dio paso con mucha frecuencia a la exacerbación de aspectos

7 De acuerdo con los planteamientos que hace Musgrave en su texto de Hacienda Pública, puede concluirse que los bienes públicos son bienes que responden a las características de la «no rivalidad» en el consumo y «la imposibilidad de exclusión». 
profundamente arraigados en la cultura empresarial: búsqueda de rentas, prácticas cuasi monopólicas y comportamientos clientelistas.

Los fracasos y las distorsiones del ajuste, así como las rigideces y sesgos del mercado fueron considerados como consecuencia del mal manejo de las políticas públicas o a la falta de una autoridad efectivamente desvinculada de los intereses particularistas. En esta línea de razonamiento, las fallas en el ajuste se debían, en definitiva, a problemas de ejecución, mucho más que a cuestiones de diseño o de contenido. El Estado debía ponerse a punto, y poner a punto a la sociedad, para la ejecución exitosa de las reformas.

Al conjunto de medidas que adoptaron los Estados, coordinadas por una élite tecnocrática, relativamente aislada de los demás actores sociales y políticos y que concentró su atención, básicamente, en la liberalización comercial y en la privatización de los activos del Estado como respuesta a las exigencias y condiciones de los organismos multilaterales de crédito para permitir el acceso a nuevos empréstitos de la banca internacional se ha conocido como «reformas de primera generación».

Las «reformas de primera generación» se inician en América Latina en la década de los ochenta mediante la adopción de «programas que combinaron una política de ajuste macroeconómico, destinada a corregir los graves desequilibrios fiscales, y una política de cambio estructural, con miras a establecer los elementos básicos para el desarrollo del modelo de economía hacia fuera» (García Chourio, 2003:94). El objetivo fundamental era la racionalización de los recursos financieros del Estado mediante la eliminación de funciones gubernamentales, disminución de los gastos (corrientes y de inversión), reducción del personal, privatizaciones, desregulación y descentralización como se desprende del Consenso de Washington.

En la mayoría de los países de América Latina las reformas de primera generación fueron llevadas a la práctica bajo programas de ajuste que implicaron un convenio conjunto con el Banco Mundial y el FMI, denominados ajustes estructurales con crecimiento, bajo la doble condicionalidad de estos organismos (García Chourio, 2003:94). Esta doble condicionalidad significaba que las medidas de ajuste fiscal implementadas bajo la supervisión del FMI se efectuaban paralelamente con la transformación del aparato estatal que el modelo neoliberal requería, efectuándose este último proceso bajo la estricta asistencia técnica y financiera del Banco Mundial, el cual hasta mediados de los noventa manejó y defendió a ultranza la tesis de la minimización del Estado basada en la teoría de la elección pública.

A mediados de la década de 1990, el Banco Mundial modifica su tesis anterior de minimización del Estado argumentando la necesidad de incluir las instituciones y la gestión pública en el conjunto de cuestiones que deben ser 
sometidas a reforma, con el fin de aumentar la eficacia de sus programas de ajuste estructural y dinamizar los procesos de desarrollo. La orientación amistosa al mercado requiere mejorar el funcionamiento de las instituciones públicas y la formulación y ejecución de las políticas gubernamentales, elevar la calidad y la eficacia de la gestión estatal, así como reducir los controles políticos o fiscales y ampliar los márgenes de acción de los mercados (Banco Mundial, 1997).

El ajuste económico, resumido en el «Consenso de Washington» o en las llamadas «reformas de primera generación», demanda reformas profundas en el diseño y funcionamiento del aparato estatal, y no sólo la reducción de éste a su expresión mínima. La cuestión es la eficacia del Estado una vez que éste ha alcanzado su tamaño óptimo. Esta es, se afirma, la dimensión ausente en el «Consenso de Washington» que en adelante se conocerá como las reformas institucionales o de «segunda generación».

Para América Latina se inicia, durante la década del noventa, una agenda de políticas y programas orientados a mejorar la capacidad administrativa e institucional del Estado, en paralelo con la ejecución de medidas de las de primera generación. Tal superposición de reformas, además de obedecer al avance, en procura de consolidar el modelo de mercado, obedeció a que las crisis posteriores a la primera generación, llevaron a un replanteamiento del modelo que al ser imposible regresar, lo que buscaba era introducir los cambios que permitieran corregir las consecuencias negativas de las reformas de primera generación.

Desde esta perspectiva, las reformas de segunda generación han representado una revitalización del papel del Estado en lo atinente al desarrollo económico, minimizado en la primera oleada de reformas, pero rescatado con las de la segunda, bajo el argumento de que la creación de una serie de dispositivos institucionales públicos les facilita a los agentes privados operar con un margen de menor incertidumbre.

García Chourio sostiene que los nuevos planes de reforma se han dirigido a la búsqueda de: «a) Eficiencia de los servicios públicos, a ser alcanzada por la optimización de los recursos financieros vía el estímulo de la competición administrativa de los recursos humanos y financieros; b) efectividad; c) democratización, involucrando a la comunidad en las decisiones relativas a las acciones públicas; y d) descentralización, hacia las esferas subnacionales, de las responsabilidades de provisión de infraestructura y de los servicios sociales» (García Chourio, 2003:94).

Las «reformas de primera generación» se dieron en medio de una percepción social sobre la grave crisis fiscal e inflacionaria que planteaba la necesidad de superarla a como diera lugar, lo cual permitió que se dieran consensos 
con relativa facilidad, entre los diferentes actores acerca de las medidas que debían adoptarse. Una situación bien diferente se presenta con las «reformas de segunda generación» que por estar dirigidas a la configuración de un nuevo modelo, han implicado diversas visiones, en muchos casos opuestas, entre los distintos actores sociales, sobre la naturaleza de las transformaciones. Pero adicionalmente, se dice que mientras que las reformas de primera generación tenían un carácter coyuntural, las de segunda generación se han caracterizado por ser, en su mayoría, de largo plazo, lo cual implica, que estas hayan sido políticamente mucho más complejas y difíciles de aplicar porque supone la presencia de distintos intereses que deben ser negociados.

El mismo García Chourio sostiene que a las dos generaciones de reforma corresponde enfoques teóricos distintos, sobre los cuales se sustentan las medidas adoptadas. En primer lugar, las medidas adoptadas por las «reformas de primera generación» se fundamentan teóricamente en la teoría de la elección racional o llamada también el enfoque de las expectativas racionales, mientras que las de «segunda generación» se apoyan en una corriente teórica que ha venido tomando mucho auge en los últimos tiempos, conocida mayoritariamente en distintos escenarios como el neoinstitucionalismo.

El enfoque de las expectativas racionales parte de una premisa netamente economicista que supone que en un contexto de múltiples opciones los individuos eligen de manera racional aquella que implique menos sacrificios y reporte mayores beneficios. De esta premisa se desprende el principio individualista de la acción a partir de un cálculo racional, el cual constituye uno de pilares de la escuela del Public Choice $e^{9}$ que tanta influencia ha tenido en los procesos de reforma.

Como consecuencia de los resultados poco alentadores que ofrecían las «reformas de primera generación», emerge el enfoque neoinstitucional que concibe las reformas como un proceso de creación de instituciones acordes para el buen funcionamiento del mercado, reconociendo en el Estado un mecanismo básico para reducir los costos de transacción en las operaciones, presentándose de esta manera un giro conceptual, en el que se deja de lado el enfoque de las expectativas racionales.

De las medidas de choque (liberalización, apertura comercial y reducción del Estado entre otras), muy utilizadas por las «reformas de primera generación» se ha pasado en los últimos años a las «reformas de segunda generación»,

8 Existe una bibliografía bastante amplia relacionada con las diferentes maneras de abordar el estudio de las instituciones, entre las que se pueden destacar: Instituciones, cambio institucional y desempeño económico, Douglas C. North, FCE, México, 1995. El redescubrimiento de las instituciones, James March y Johan Olsen. FCE, México, 1997. El nuevo Institucionalismo, B. Guy Peters, Gedisa, Barcelona, 2003.

9 La escuela del Public Choice o «elección pública», representada por James Buchanan y Gordon Tullock, se sustenta en la creencia de la racionalidad del mercado a partir de la agregación de preferencias individuales y del movimiento autónomo del dinero debido al libre juego de la oferta y la demanda. 
centradas en construir y reconstruir instituciones estatales que le permitan operar al mercado de forma eficiente, ofreciéndole seguridad a los agentes económicos «en la medida en que las instituciones contribuyen a aminorar la incertidumbre que caracteriza a los mercados, al reducir la volatilidad de los capitales y su carácter especulativo» (García Chourio, 2003).

En el mismo texto al que se viene haciendo referencia, García Chourio, citando a Rodrik Dani, sostiene que existen cinco tipos de instituciones básicas de apoyo al mercado: una, los derechos de propiedad, referidos a dispositivos legales y administrativos que garanticen la propiedad intelectual y las patentes; dos, las instituciones de regulación, tales como las superintendencias de bancos y de seguros; tres, las instituciones para la estabilización macroeconómica, como bancos centrales independientes y administraciones tributarias autónomas; cuatro, las instituciones de seguridad social, dirigidas a la compensación del desempleo y a la protección de la sindicalización; y cinco, instituciones para la administración del conflicto social, tales como el imperio de la ley y la autonomía del poder judicial, la transparencia de la gestión pública, sindicatos independientes, elecciones libres y organizaciones políticas representativas (García Chourio, 2003).

\section{Algunas consideraciones acerca del derecho regulativo}

En concordancia con el aumento de las funciones intervencionistas del Estado en la vida económica y social, el derecho también ha tenido que incorporar nuevas formas de regulación para dar respuesta legal a las demandas que le plantea el nuevo rol del Estado. En otras palabras, podría decirse que el Estado por medio del derecho, fija las líneas de intervención política con fines de integración social y promueve regulativamente los valores e intereses que deben orientar las relaciones sociales (Calvo García, 2005).

Los instrumentos de regulación que surgen con ocasión de la crisis de los años treinta son una respuesta a las demandas de racionalización que el sistema económico le plantea al Estado para corregir las imperfecciones del mismo y así, restaurar las reglas del mercado que estaban puestas en cuestionamiento por su ineficacia, por lo cual, los objetivos regulativos de este período son de carácter puramente económico porque, de una parte se orientan a superar la sensación de fracaso de un sistema económico de mercado en el que imperan los principios de la libre empresa y la competencia, pero a la vez, se propone a rescatar a los sectores económicos más afectados como lo eran los sectores industrial y financiero.

La regulación económica tuvo un gran desempeño al contribuir de manera importante en la superación de la crisis y a elevar las tasas de crecimiento durante el resto del período, hasta llegar a los años sesenta en los que comienza a reclamarse un papel distinto a los puramente económicos o de racionalidad 
del sistema para que la intervención del Estado y la regulación jurídica diera cuenta de los aspectos relacionados con el bienestar físico y moral de las personas como los atinentes a la protección de la salud y la seguridad, la educación, el medio ambiente, superación de la pobreza y la discriminación, el empleo y el acceso a la vivienda, entre otros. A la regulación de estas nuevas responsabilidades que asume el Estado, distintas de la regulación económica o tradicional se le va a denominar regulación social.

«La nueva regulación social busca proteger a los ciudadanos estableciendo pautas de comportamiento obligatorias para los agentes económicos y sociales privados sometiendo sus actuaciones a un control público permanente. La intervención estatal que promueve la regulación social va mucho más allá del control de precios y servicios y de las limitaciones de acceso a un sector industrial o utilidad pública que había caracterizado a las iniciativas de regulación económica» (Calvo García, 2005: 26).

Es a partir de las demandas sociales que el Estado, en su nuevo rol, se ve obligado a asumir nuevas funciones, en esta oportunidad de carácter asistencial para garantizar unos mínimos de bienestar. Para ello, nuevamente se vale del derecho mediante el cual, no solo limita, controla y obliga sino que además promueve valores e intereses sociales, tomando distancia frente a la ideología jurídica liberal, al no reducir su papel de garantizar los derechos y libertades fundamentales del individuo, sino que, en adelante, va asumir un papel mucho más activo, al fomentar, promover y obligar a particulares y entes del Estado a su cumplimiento. En otras palabras, podría decirse que el derecho se vuelve teleológico. ${ }^{10}$

En el Estado intervencionista, la orientación del derecho hacia fines implica su utilización como medio para la formulación e implementación de las políticas públicas, lo cual supone que debe estar permeado por diversos criterios y determinantes materiales como podrían ser los aspectos económicos, políticos axiológicos y técnicos, entre otros. Esto lo obliga a hacer tránsito de un espacio de racionalidad formal, hacia nuevas formas de pensamiento en las que predomina la racionalidad material, lo cual, conlleva cambios importantes en las dinámicas jurídicas orientadas a la realización y aplicación del derecho. Dicho de otra forma, la realización del derecho útil o regulativo solo es concebible en términos de ejecución de políticas públicas encaminadas a conseguir resultados acordes con valores, objetivos e intereses sociales (Calvo García, 2005). 
Una consecuencia adicional del intervencionismo estatal y la consiguiente «materialización» del derecho consiste en que se produce un aumento de complejidad de su estrucutura y de su contenido, así como de las dinámicas jurídicas mediante las que se realiza. Po lo que: «La realización efectiva del derecho regulativo exige, en primer lugar, la creación y puesta en funcionamiento del marco jurídico-burocrático de intervención que asuma el deesarrollo de programas y la aplicación de las normativas de protección y promoción de valores y fines sociales; lo que oblliga a una regulación cada vez más compleja y a la "movilización" de amplios medios económicos, institucionales, técnicos y humanos necesarios para la realización de los fines y objetivos regulativos: dotaciones presupuestarias, diseño e impulso de políticas públicas y programas de intervención; creación o adaptación de "aparatos" e infraestructuras de intervención (pública y semipúblicas); incorporación de expertos, establecimiento de controles positivos y negativos, evaluaciones, etc.» (Calvo García, 2005: 11-12).

En tales circunstancias, el Estado intervencionista disponía por un lado de condiciones para atenuar tensiones, neutralizar presiones y bloquear eventuales amenazas a la legitimidad institucional, y, por otro, contaba con la flexibilidad decisoria necesaria para estimular, promover, disciplinar y regular el crecimiento así como para enfrentar los riesgos de la inestabilidad coyuntural, pudiendo de esta manera preservar el proceso económico de problemas disfuncionales (Faria, 2000).

Sin embargo, ante la crisis financiera que comienza a vivirse en los años setenta, acompañada del incremento en los niveles de inflación, la caída de las rentas tributarias, el incremento del gasto público, el aumento del desempleo con las consiguientes tensiones y presiones sindicales, los enfrentamientos entre la política económica y la política social, la poca efectividad de las medidas adoptadas para disminuir las desigualdades, las políticas Keynesianas y el Estado social que las dirigia y orientaba, llega a sus límtes y se agotan progresivamente todas la bondades que se le atribuían.

Pero la inflación no es solamente económica, también lo es en la producción de carácter juridico normativo, en la medida en que la expedición de leyes se hizo de manera herrática y desordenada aumentando el número de materias, actividades y comportamientos regulados, dando como resultado «una ruptura en la organización, en la unidad lógica y en la racionalidad sistémica del ordenamiento jurídico y, como consecuencia, la pérdida de la propia capacidad de predeterminación de las decisiones concretas por medio del derecho positivo. Esa disfuncionalidad creciente tanto del Estado "social" o regulador como de su instrumental normativo configura un proceso que ha sido llamado como "ingobernabilidad sistémica" o "crisis de gobernabilidad" por los científicos políticos y como "inflación legislativa", "juridificación” o "sobrejuridificación” y "trilema regularizador"por los sociólogos y teóricos del derecho» (Faria, 2000). 
Entre las consecuencias que se desprenden de la hiperinflación normativa, se encuentra la desvalorización (Calvo García, 2005) progresiva del propio derecho positivo, impidiendo el ejercicio de las funciones reguladoras y de control, así como generando incongruencias y contradicciones propias de su desarrollo que en su efecto acumulativo afectan el sistema jurídico. ${ }^{11}$

Finalmente, es necesario recordar que así como se plantearon soluciones de carácter económico, denominadas medidas de ajuste estructural o reformas de primera generación, también se pusieron en práctica las de carácter institucional o reformas de segunda generación que lo que buscaban era mejorar el desempeño del Estado y no, la reducción de su tamaño como lo pretendian las de primera generación.

Una de las medidas del «Consenso de Washington» que ha tomado una gran relevancia jurídico-política, no obstante tener un origen económico es la llamada desregulación, entendida en un principio como el proceso por medio del cual era necesario desmontar el conjuto normativo que regulaba temas centrales del Estado intervencionista y que van a ser duramente criticados por la tendencia neoliberal que las considera grandes impedimentos para la plena realización de las leyes del mercado y obstáculo del principio de la libre competencia y de la iniciativa privada.

No obstante, contrario a lo que podría pensarse, de la mano de las reformas de segunda generación o institucionales, a mediados de los noventa, el debate toma un rumbo diferente y comienza a hacer carrera el concepto de que la desregulación no significa la usencia de normas o anomia ${ }^{12}$ como la denominan algunos, sino que por el contrario, se identifica con el desplazamiento de normas intervencionistas propias del Estado social por otras cuya función se limita a asegurar la autonomia privada y la libre competencia entre sujetos que operan en el mercado. En tal sentido, la desregulación constituiría una técnica normativa de mayor utilidad para la globalización.

Al igual de lo que sucede con el fenómeno de la regulación, la desregulación no es ajena a la ambigüedad y diversidad de significados que se le asignan y por ello

\footnotetext{
11 Entre las incongruencias y contradicciones del derecho positivo del Estado intervencionista o regulador a las que se refiere Faria, se destacan: a) la gradual burocracia de la vida económica y social provocada por la conversión del derecho en un instrumento de gestión macroeconómica, b) los efectos laterales involuntarios o no previstos por el legislador en la regulación de determinadas áreas y sectores de la sociedad, c) creciente ineficacia de sus normas para la resolución adecuada socialmente y orientada prospectivamente de los conflictos, d) los faltantes progresivos de legitimidad del ordenamiento jurídico en la medida en que el proyecto de organización social y económica subyacente a sus programas finales, o sea orientados por el resultado, van dejando de ser aceptados de una manera consensual, e) continua particularización del derecho regulador en ramas y sectores muy específicos, volviendo el sistema jurídico como un todo sin condiciones de ofrecer un mínimo de certeza y seguridad, f) la implantación de la influencia interdisciplinaria, ya sea en plano legislativo, ya en el de la jurisprudencia exigida por el aumento de la complejidad técnica de las materias reguladas originando en contra partida la superación del instrumental técnico-jurídico tradicional, g) las dificultades de la dogmática jurídica ante todas esas disfuncionalidades para continuar ejerciendo sus funciones básicas de control a la consistencia del derecho legislado y a forjar modelos teóricos para el encuadre de la producción normativa.

12 Un análisis ilustrativo e interesante acerca del camino que ha tomado el análisis de la desregulación se puede consultar en (Marcilla, 2005).
} 
se puede afirmar que, desde el punto de vista teórico jurídico (Marcilla, 2005), la desregulación puede considerarse una manifestación del pluralismo jurídico, en tanto que, desde el punto de vista filosófico político, suele vincularse al proyecto político neoliberal y a la práctica de privatización de los servicios públicos.

En la actualidad, no se puede afirmar que la regulación o reglamentación económica ha disminuido, en términos cuantitativos, como resultado de la exigencia que se hace desde corrientes neoliberales de desregular la economía, o de disminuir la cantidad de normas que condicionan su actuación. Lo que ha sucedido realmente, es un cambio de objetivo o propósito. Mientras que en el período intervencionista la regulación se proponía orientar la dirección general de la economía, en la actualidad se trata de garantizar el juego libre y transparente de los agentes económicos, para lo cual se requiere una reglamentación numerosa y detallada.

Corresponde aclarar que las funciones reguladoras que sustituyen a las directamente productivas, son diferentes a las desactivadas a través de las políticas de desregulación antes mencionadas. La diferencia esencial entre unas y otras es el carácter público de los bienes o servicios involucrados.

En efecto, la nueva regulación pretende abarcar las relaciones entre el estado, los prestadores y los usuarios, en cuanto a las condiciones en que los nuevos operadores prestan servicios públicos. En cambio, las regulaciones suprimidas en el marco de la reforma estatal apuntaban, más bien, a la aplicación de reglas de juego mediante las cuales el Estado intentaba preservar o corregir determinados desequilibrios económicos o sociales, como en el caso del establecimiento de precios sostén; el aprovisionamiento de ciertos insumos críticos; el uso de stocks de intervención para regular los mercados; la fijación de la paridad cambiaria, el salario mínimo o la tasa de interés bancaria. En estos casos, existe un «interés público» pero no un «servicio público» afectado.

\section{El diseño institucional para el ejercicio de la regulación}

Una característica común que es posible identificar en las llamadas reformas de primera y segunda generación, además de la liberalización de los mercados, han sido los procesos de privatización realizados en los diferentes países de Europa y América Latina, en cumplimiento de las medidas, sugerencias, recomendaciones o imposiciones hechas por los organismos multilaterales de crédito (Banco Mundial, FMI), tendientes a disminuir el tamaño del Estado y a contribuir en la solución del déficit fiscal.

Han sido, precisamente, los servicios públicos de infraestructura (transporte, energía, telecomunicaciones) las principales actividades objeto de regulación por hacer parte de la agenda privatizadora. Pero para avanzar en el diseño 
institucional $^{13}$ de estos procesos, no es suficiente con establecer qué actividades se pueden o deben privatizar, sino que es absolutamente necesario, definir con anticipación, al menos dos temas: uno el marco regulatorio del servicio o actividad que se va a privatizar y dos, la autoridad, el ente o entidad encargada de la actividad reguladora. Desafortunadamente, son pocos los casos en América Latina, ${ }^{14}$ en los que estos dos procesos han precedido el traspaso de las empresas estatales a manos privadas.

La independencia y autonomía de las autoridades, entes, entidades o agencias ${ }^{15}$ encargadas de atender la actividad reguladora, es un tema de gran importancia en la actualidad, debido a que surge como una condición necesaria para que tenga buenos resultados que se puedan transferir a los consumidores. Pero adicionalmente, porque no se ha resuelto el intento de construir un modelo que permita, en términos empíricos, medir el nivel de independencia y autonomía que garantice que no va a ser capturada por los diferentes grupos de interés o agentes regulados. En este sentido se podría asumir que una regulación efectiva debería ser sinónimo de regulador independiente

Al hablar de independencia se hace referencia al grado de autonomía que puede tener el regulador para tomar decisiones aisladas de los agentes o funcionarios estatales y de las firmas reguladas, asumiendo que la regulación de servicios públicos tiene como finalidad: proteger a los consumidores del abuso de firmas con poder de mercado, proteger a los inversores del oportunismo gubernamental y promover la eficiencia económica.

El grado de independencia de los entes reguladores, variará de un país a otro, dependiendo de las competencias dadas al organismo, del personal calificado y de los recursos disponibles. Con base en estos elementos, Sifontes plantea, en el artículo al que se viene haciendo referencia, que las agencias reguladoras pueden tomar diferentes formas, entre la que se señalan:

o Agencia incorporada al ministerio del sector: actúa como una subsecretaría y no posee financiamiento propio

o Agencia semi-autónoma: tiene ciertos poderes, con decisiones sujetas a la revisión de ministerios o comisiones

o Agencia totalmente autónoma: muchas veces tienen igual rango que el ministerio, poseen financiamiento propio y el personal se designa por períodos definidos.

13 Un análisis detallado del tema se encuentra en Godin, 2003.

14 Una aproximación a este balance lo hace Oszlak (2004).

15 Un análisis detallado sobre el surgimiento, características, modalidades y diferencias entre este tipo de personas jurídicas se puede consultar en Fernández Rojas, 2003, 2004, 2005. También se puede consultar en Contribuciones a la economía. Revista Académica Virtual (www.eumed.net/ce/ds-regulat.htm). 
o Agencia incluida dentro de la estructura del sector: generalmente el operado es quien regula.

o Ausencia de agencia reguladora, delegando a los tribunales de justicia las funciones correspondientes a las agencias: las decisiones en materia de regulación son tomadas por los tribunales de justicia.

De las tres investigaciones hechas por el profesor Fernández Rojas, llama la atención que sean más las diferencias que las similitudes las se pueden identificar entre los modelos de España (Fernández, 2005) y Francia (Fernández, 2004), si se tienen en cuenta las características, la justificación de su existencia y las funciones y competencias que el autor les señala.

Fernámdez considera que las dos características esenciales que definen a las denominadas administraciones independientes en España son, por una parte, su naturaleza de administración activa, es decir, que reconoce derechos e impone obligaciones a los particulares $\mathrm{y}$, por otra (a diferencia de la administración general del Estado y los organismos públicos funcionalmente descentralizados) su extraordinaria autonomía en el ejercicio de sus competencias, en detrimento de algunas de las facultades de dirección que le asisten al gobierno en sus relaciones ordinarias con la administración; mientras que, la característica esencial que define a las numerosas autoridades administrativas independientes en Francia, es su extraordinaria autonomía en el ejercicio de sus competencias, en detrimento de las facultades jerárquicas que le asisten al gobierno en sus relaciones ordinarias con la administración.

Respecto a la justificación de la existencia de tales entidades, plantea el autor que para el caso de España, responde a tres desafíos fundamentales:

- La reconstrucción de la legitimidad institucional, deteriorada por una profunda desconfianza frente a la manipulación partidista de las administraciones públicas.

- El perfeccionamiento de los mecanismos institucionales para la protección de la salud pública, la preservación de un medio ambiente sano, y la garantía a los derechos y libertades fundamentales.

- La defensa de un mercado eficiente y con alta calidad e incertidumbre competencial, para sostener y potenciar un elevado nivel de desarrollo, y

- El incremento de la competitividad, la eficiencia y la calidad de las administraciones públicas en el marco de la Unión Europea.

De otra parte, los desafíos que justifican la existencia de estas entidades en Francia, son relacionados por el autor con: 
- La reconstrucción de una legitimidad institucional puesta en entredicho por la manipulación partidista de las administraciones públicas.

- El perfeccionamiento de los mecanismos institucionales que garanticen escrupulosamente el respeto a los derechos fundamentales y la participación democrática.

- La defensa de un mercado eficiente y con alta calidad competitiva, que permita sostener y potenciar los niveles de desarrollo social alcanzados.

- Asimismo, las administraciones independientes están inspiradas en el proceso de construcción de la Unión Europea, y en los principios rectores que orientan el derecho comunitario europeo.

Finalmente en lo relacionado con las funciones y competencias, sostiene que mientras en España se les asignan: normativas de supervisión (autorización, vigilancia y sanción); en Francia corresponde a reguladoras, supervisoras de autorización, vigilancia y sanción, y complementarias de resolución de conflictos y asesoramiento

De lo anterior se puede colegir que si bien es cierto en los modelos español y francés, al igual que el norteamericano, se le ha otorgado una altísima dosis de independencia y autonomía a este tipo de entidades, es poco lo que se ha logrado en materia de división de trabajo y especialidad funcional, porque en ambos casos, se combinan funciones de regulación, inspección y vigilancia. Esta situación puede generar dificultades en términos de duplicidad de funciones o colisión de competencias con otras entidades del Estado o aún peor convirtiendo estos organismos en juez y parte.

\section{La capacidad institucional para el ejercicio de la función reguladora}

Las reformas de segunda generación, como ya se dijo, son de carácter institucional y van dirigidas fundamentalmente a modificar el papel del Estado frente a la economía, obligándolo a sustituir su rol de productor directo de bienes y prestador de servicios, por el de regulador de los mercados en los que empezaban a operar los nuevos agentes económicos, como resultado de los procesos de privatización y tercerización de que fueron objeto las empresas que por mucho tiempo fueron operadas directamente por el Estado.

La función reguladora que debe asumir el Estado, en su nuevo rol, presenta dos características importantes, entre muchas otras más, que vale la pena resaltar. De una parte, se considera que el cumplimiento de dicha función es inevitable, porque el Estado no puede abandonar la responsabilidad que tiene de velar por la «producción y entrega de esos bienes y servicios, en tanto tengan un carácter público y, por lo tanto, deben ser ofrecidos a los 
usuarios en forma oportuna, no discriminatoria, con la calidad adecuada y a costos razonables» (Oszlak, 2004:139).

De otra parte, así parezca demasiado obvio, la regulación que debe ejercer el Estado en los actuales momentos no es «la misma de los sesenta o setenta. No se orienta a reemplazar el mercado cuando éste falla, sino apoyarlo, profundizarlo, complementarlo y, en no pocas ocasiones, crearlo, contribuyendo así a reducir los costos de transacción derivados de la información asimétrica e insuficiente, asociada, por lo general, a los sistemas de gestión burocrático-centralizados»» (Stark, 2001:153).

Ante el nuevo escenario en el que el papel regulador del Estado debe primar sobre las funciones tradicionales de productor directo de bienes y prestador de servicios, que aún no ha abandonado por completo y, que seguramente tardará mucho más tiempo para hacerlo, el Estado debe desarrollar la institucionalidad y las organizaciones que sean capaces de cumplir efectivamente con la tarea señalada, creándolas en algunos casos y en otros modificando las existentes con el fin de adecuarlas a la nueva realidad. Este proceso de reconstrucción supone, entre otras cosas, desarrollar la capacidad estatal de regulación tanto en su misión como en sus sistemas de gestión y gerencia.

El proceso de creación de la nueva institucionalidad reguladora, o de adecuación de la ya existente, no cuenta con una receta general que sea aplicable a todos los casos y en todos los países, quizá porque no existe una teoría de aceptación universal sobre la regulación, ni mucho menos, formas de organización y gestión de aplicación inmediata y de validez general. Lo que existe es un conjunto de prácticas reguladoras, que de manera empírica, han venido aplicando los diferentes países, de acuerdo con su realidad institucional.

En el campo de las organizaciones, por ejemplo, se han ido creando entidades de muy diversa naturaleza, con marcos jurídicos distintos, variados niveles de autonomía, relaciones funcionales y jerárquicas muy difusas y con diferentes denominaciones, tales como, superintendencias, comisiones de regulación, entes reguladores, agencias o institutos, sin olvidar que en ocasiones, algunos ministerios, departamentos administrativos, u otro tipo de entidades, también cumplen algunas funciones relacionadas con la regulación. Una situación similar se presenta al observar los sistemas de gestión y gerencia que se ponen en práctica para la operación y el direccionamiento de las entidades reguladoras.

No se puede olvidar que así como le correspondió a la administración pública burocrática la producción de bienes y la prestación de los servicios durante el período del llamado Estado interventor, será la gerencia pública la responsable de garantizar la eficacia del Estado regulador en el marco de los procesos de modernización del Estado, para lo cual deberá acudir a la utilización y puesta en práctica de nuevas tecnologías, principios, sistemas, procesos y procedimientos 
mucho más ágiles y flexibles en la atención de los usuarios clientes, acudiendo a la profesionalización de los servidores públicos y a la democratización de las prácticas reguladoras

A pesar de existir una amplia e importante literatura que da cuenta de la regulación como una de las funciones a las que mayor atención debe poner el Estado, en el actual escenario, son pocos los estudios e investigaciones que analizan y evalúan las particularidades de cada sector, en lo relacionado con la capacidad o incapacidad para atender las diferentes actividades que conforman la función reguladora, la cual puede referirse desde la concesión de licencias y autorizaciones a operadores, pasando por la aprobación de tarifas, la revisión del cumplimiento de estándares técnicos operacionales, promoción y defensa de la competencia, hasta la aplicación de sanciones por incumplimiento, entre otras.

Para contribuir en la solución de esta situación, Oscar Oszlak propone un modelo analítico y un esquema metodológico para el análisis de la función reguladora y sus diferentes manifestaciones e introduce el concepto de déficit de la capacidad institucional (DCI) (Oszlak, 2004:141) para aludir a los diversos tipos de factores que pueden impedir el normal ejercicio de las variadas funciones regulatorias.

El modelo analítico que propone Ozlak (2004), parte de ubicar en los vértices de un triángulo a los diferentes actores que participan en la regulación. En un vértice, ubica al «Estado regulador», en otro a los «prestadores de servicios» $\mathrm{y}$ en el otro a los «usuarios». Sostiene que en el vértice asignado al Estado se deciden cuestiones relativas al ámbito de la regulación, los aspectos que abarca y sus alcances, los criterios de aplicación, los marcos jurídicos y los mecanismos institucionales. En el vértice de la producción, los prestadores, dentro del marco regulatorio establecido, adoptan políticas relativas a los volúmenes de los servicios ofrecidos, los tipos de usuarios, las tecnología a emplear, los costos y precios y las inversiones requeridas, entre otros. En el vértice del consumo se decide la utilización o no de los servicios y los eventuales sustitutos.

Adicionalmente expresa Oszlak, que se presentan diversos tipos de relaciones entre los actores ubicados en los diferentes vértices del triángulo. Precisa un primer vínculo entre regulación-prestación, en el que los problemas centrales que se plantean son los de la capacidad institucional, legitimidad y poder coercitivo de los órganos reguladores para ejercer el rol. En el vínculo prestación-consumo se refiere al grado en que los servicios que se prestan satisfacen las necesidades de los usuarios y finalmente en la relación regulación-consumo se verifica en qué medida queda amparado el interés de los usuarios.

De las relaciones descritas, el autor decide considerar, especialmente, las que tienen lugar en el vértice de la regulación, «ya que la densidad y orientación de esas interrelaciones reflejarán, en última instancia, la capacidad institucional del Estado para cumplir eficazmente su rol regulador» (Oszlak, 2004:144). 
Definidas las relaciones entre los vértices, plantea dos temas adicionales que deben tenerse en cuenta en el modelo analítico. Uno se refiere a la identificación de algunos objetivos que hacen parte de la institucionalidad regulatoria y sus alcances, acerca de los bienes que se pretende resguardar a través de la regulación. El otro se refiere a las funciones de la regulación, las cuales, contempla en dos niveles. En un primer nivel señala las de carácter general que comprenden al control del cumplimiento de las obligaciones a cargo de los prestadores privados de servicios públicos y la protección del derecho de los usuarios, a las que denomina como cuasilegislativas, cuasijudiciales y administrativas y de gestión.

El otro nivel, las denomina como funciones típicas de los entes reguladores, cuyas características implican el despliegue de distintas capacidades de gestión y constituyen el elemento diferencial para comenzar a desagregar los factores que generan déficit en la capacidad institucional de los entes para cumplir con su misión. Las funciones a las que hace referencia son (Oszlak, 2004:150):

Concesión de licencias y autorización a operadores. Incluye el otorgamiento, la suspensión, la declaratoria de caducidad, la revocatoria de concesiones y autorizaciones y la aplicación de pagos que deben hacer los operadores.

Aprobación de tarifas. Consiste en la determinación y modificación de tarifas, el seguimiento de su aplicación y la publicación y difusión de las mismas

Revisión del cumplimiento de estándares técnico operacionales. Se refiere a la fiscalización de la calidad, seguridad, oportunidad, y acceso pleno a los servicios prestados, de acuerdo con los estándares técnicos establecidos en los marcos regulatorios y en los contratos de concesión.

Proposición de normas y reglamentos. Incluye el análisis, la evaluación y el diseño de normas y reglamentos para la prestación de los servicios, así como la promoción de su adopción por los prestadores.

Promoción y defensa de la competencia. Se orienta a la detección de prácticas monopólicas y la atención de solicitudes y consultas sobre posibilidades de fusiones, firma de convenios, contratos, etc.

Seguimiento del grado de cumplimiento de obligaciones contractuales. Consiste en la determinación de criterios para la verificación de aspectos técnicos, contables y jurídicos, así como la realización de inspecciones para verificar el cumplimiento de compromisos de inversión, mejora de servicios, custodia y preservación de bienes.

Atención de reclamos y controversias. Incluye, entre otras, la resolución de controversias entre empresas, la atención de reclamaciones de usuarios y la resolución de recursos jurídicos 
Aplicación de sanciones y multas por incumplimiento. Se refiere a la determinación y aplicación de sanciones a los responsables, ante la detección de situaciones de cumplimiento del marco regulatorio o de los contratos de concesión.

Como es de esperarse, y así lo cree Oszlak, las funciones típicas de los entes debe reflejarse en su organización interna, en la distribución de responsabilidades, en las normas específicas que regulan cada una de las modalidades de intervención regulatoria, en los perfiles de los puestos de trabajo ocupados, en la asignación de los recursos financieros y en otros aspectos institucionales que pueden ser requeridos según la especialización de la función.

Las funciones descritas constituyen la primera dimensión analítica del modelo, pueden estar expuestas a diferentes tipos de déficit de capacidad institucional que afectan las posibilidades de que estas funciones sean cumplidas adecuadamente. Para su comprensión, a renglón seguido se define como capacidad institucional a los recursos materiales y humanos que disponen y están en condiciones de asignar legítimamente aquellos entes estatales responsables de regular la prestación de servicios públicos por agentes privados u organismos del Estado.

La otra dimensión analítica del modelo se refiere al déficit de capacidad institucional, entendido éste como la brecha perceptible que se produce entre lo que un ente regulador se propone realizar en cumplimiento de su misión y lo que efectivamente logra conseguir. El origen de tal déficit puede deberse a factores intra organizacionales, para cuya superación el ente debe emprender acciones de fortalecimiento institucional, o a factores contextuales que operan como restricciones que el ente no está condiciones de controlar.

Sostiene el autor que existen diferentes factores que provocan deficiencias o problemas en la gestión reguladora, algunas de ellas las relaciona como: 1) las reglas de juego que rigen el proceso regulatorio, 2) las relaciones inter-institucionales que se establecen en torno a ese proceso, 3 ) las falencias de organización interna o asignación de responsabilidades, 4) las carencias de insumos físicos o recursos humanos, 5) las políticas de personal adoptadas o, 6) las capacidades individuales de las personas.

De otra parte, el esquema metodológico que adopta Oscar Oszlak (2004:158), se encuentra en estrecha relación con el modelo analítico que propone, siendo precisamente los hiatos o desenganches verificables empíricamente en el cruce de las dos dimensiones analíticas señaladas, es decir, los diferentes tipos de funciones que potencialmente forman parte de de la gestión regulatoria y los distintos tipos de déficit de capacidad institucional utilizado para clasificar las variables a las que puede atribuirse la generación de déficit.

Ambas dimensiones analíticas son exhaustivas, en el sentido que, comprenden por una parte, el universo de funciones que, típicamente, componen las 
responsabilidades de los entes reguladores y, por otra, cubren los diferentes tipos potenciales de déficit, según los supuestos empleados en la conceptualización.

Las categorías conceptuales utilizadas para el análisis de los déficit de capacidad institucional (DCI) son:

- Déficit asociado con variables contextuales de la activad de los entes.

- Déficit asociado con el marco normativo que gobierna su actividad.

- Déficit asociado con las estructuras organizativas que enmarcan sus tareas.

- Déficit asociado con los recursos humanos y materiales necesarios para su labor.

- Déficit asociado con los comportamientos individuales implícitos en el desempeño.

Al cruzar en una matriz, las funciones generales y típicas descritas en el modelo analítico con los déficit de capacidad institucional, observa el autor que surgen otras especificidades propias de la naturaleza de los servicios, que introducen nuevas dimensiones analíticas que cruzan a las otras dos. Eso lo lleva a sostener que parte de la especificidad de los entes se origina en la especialización diferencial en ciertas funciones; y parte en las características de los prestadores de los servicios, su número, tamaño, criticidad de su prestación, capacidad de las empresas para mantener situaciones de asimetría de información o de captura de los entes y otros factores de índole similar (Oszlak, 2004:159).

A modo de conclusión, se puede afirmar que el estudio de las grandes transformaciones del Estado y el derecho no pueden quedarse en el nivel puramente analítico, interpretativo, comprensivo y explicativo, es decir, en un plano meramente académico. Es absolutamente necesario bajar a un nivel mucho más empírico y concreto, tratando de establecer cuál es la capacidad institucional, organizacional, administrativa y de gestión con la que se viene desempeñando el Estado en el ejercicio de la función reguladora, identificando los diferentes factores que impiden el normal ejercicio de dicha función para diferenciarla de la forma como lo hizo durante el llamado Estado de bienestar.

\section{Referencias Bibliográficas}

Ayala Espino, José. 1996. Mercado, elección pública e instituciones. Una revisión de las teorías modernas del Estado. Facultad de Economía México: UNAM. 
Banco Mundial. 1997. Informe sobre el Desarrollo Mundial. El Estado en un mundo en transformación. Washington, Banco Mundial.

Bedoya Giraldo, Hubed. 2001. «Existencia jurídica de la regulación». Letras Jurídicas Vol. 6:1:31-45. .

Calvo García, Manuel. 2005. Transformaciones del Estado y del derecho. Bogotá: Universidad Externado de Colombia.

Calvo García, Manuel. 1999. "Transformaciones del derecho y crisis de la justicia», en Revista Derecho del Estado No 7:73-97.

Contribuciones a la economía. Revista Académica Virtual. www.eumed.net/ce/dsregulat.htm.

Faria, José Eduardo. 2000. «Economía y derecho: en el cruce de dos épocas». El otro derecho. 24: 11-46.

Fernández Rojas, Gabriel. 2005. «Las administraciones independientes de regulación y supervisión en España». Vniversitas. 109: 419-460.

Fernández Rojas, Gabriel. 2004. «Las autoridades administrativas independientes en Francia». Vniversitas. 107: 343-372.

Fernández Rojas, Gabriel. 2003. «La administración por agencias independientes en los Estados Unidos de América». Vniversitas. 106: 177-205.

García Chourio, José Guillermo. 2003. «De la primera a la segunda generación de reformas del Estado en América Latina: giro ideológico y cambio conceptual», Cuadernos de Economía. 38: 95-125.

Giraldo, César (ed.). 2002. Finanzas Públicas en América Latina: la economía política. Bogotá: Desde abajo / ESAP.

Godin, Robert E.(Compilador). 2003. Teoría del diseño institucional. Barcelona: Editorial Gedisa.

Marcilla Córdoba, Gema. 2005. «Desregulación, Estado social y proceso de globalización». DOXA. 28: 239-263.

Oramas Molina, Rafael Enrique. 2003. «La regulación: un concepto aún por definir». En: III Jornadas de derecho constitucional y administrativo. Bogotá: Universidad Externado de Colombia.

Oszlak, Oscar. 2004. «Privatización y capacidad de regulación estatal: una aproximación teórico- metodológica». En: Luiz Carlos Bresser Pereira, Nuria Cunill Grau, Leonardo 


\section{Alberto Giraldo Saavedra}

La función reguladora del estado y el derecho, artículo de Reflexión

Garnier y Adam Przeworski , Oscar Oszlak (eds.). Política y Gestión Pública. 139-183. Buenos Aires: Fondo de Cultura Económica.

Oszlak, Oscar y Ruth Felder. 1988. «La capacidad de regulación estatal de la Argentina: Quis custodiet custodes?». En: La Argentina que viene. Aldo Isuani - Daniel Filmus (comp.), Buenos Aires: Flacso/Eudeba.

Porras Nadales, Antonio J. 2002. «El derecho regulativo». En: Revista de Estudios Políticos (Nueva Época) No 117:49-72.

Rivera Urrutia, Eugenio. 2004. «Teorías de la regulación en la perspectiva de las políticas públicas». En: Gestión y Política Pública, volumen XIII, No 2:309-372.

Stark, Carlos. 2001. «Regulación, agencias reguladoras e innovación de la gestión pública de América Latina». En: Una nueva gestión pública para América Latina. CLAD.

Villas, Carlos M. 2000. «¿Más allá del consenso de Washington? Un enfoque desde la política de algunas propuestas del Banco Mundial sobre reforma Institucional». Revista del CLAD Reforma y Democracia. No 18: 1-30 (versión electrónica:http://www.clad. org/portal/publicaciones-del-clad/revista-clad-reforma-democracia/articulos/018octubre-2000/bfmas-alla-del-consenso-de-washington-un-enfoque-desde-la-politicade-algunas-propuestas-del-banco-mundial-sobre-reforma-institucional-1). 